\title{
Dietary flavonoid intake and weight maintenance: three prospective cohorts of 124086 US men and women followed for up to 24 years
}

\author{
Monica L Bertoia, 1,2 Eric B Rimm,, 1,2,3 Kenneth J Mukamal,, 1,4 Frank B Hu,,2,3 Walter C Willett, 1,2,3 \\ Aedín Cassidy ${ }^{5}$
}

${ }^{1}$ Department of Nutrition,

Harvard T.H. Chan School of

Public Health, 655 Huntington

Avenue, Boston, MA 02115,

USA

${ }^{2}$ Channing Division of Network

Medicine, Brigham and

Women's Hospital and Harvard

Medical School, Boston

${ }^{3}$ Department of Epidemiology,

Harvard T.H. Chan School of

Public Health, Boston

${ }^{4}$ Department of Medicine, Beth Israel Deaconess Medical

Center, Boston

${ }^{5}$ Department of Nutrition, Norwich Medical School, University of East Anglia,

Norwich, UK

Correspondence to: $\mathrm{M} \mathrm{L}$

Bertoia mbertoia@hsph.

harvard.edu

Additional material is published online only. To view please visit the journal online (http://dx.doi. org/10.1136/bmj.i17)

Cite this as: BMJ 2016;352:117 http://dx.doi.org/10.1136/bmj.i17

Accepted: 11 December 2015

\section{ABSTRACT}

\section{OBJECTIVE}

To examine whether dietary intake of specific flavonoid subclasses (including flavonols, flavones, flavanones, flavan-3-ols, anthocyanins, and flavonoid polymers) is associated with weight change over time.

DESIGN

Three prospective cohort studies.

\section{SETTING}

Health professionals in the United States.

\section{PARTICIPANTS}

124086 men and women participating in the Health Professionals Follow-up Study (HPFS), Nurses' Health Study (NHS), and Nurses' Health Study II (NHS II).

\section{MAIN OUTCOME MEASURE}

Self reported change in weight over multiple four year time intervals between 1986 and 2011.

\section{RESULTS}

Increased consumption of most flavonoid subclasses, including flavonols, flavan-3-ols, anthocyanins, and flavonoid polymers, was inversely associated with weight change over four year time intervals, after adjustment for simultaneous changes in other lifestyle factors including other aspects of diet, smoking status, and physical activity. In the pooled results, the greatest magnitude of association was observed for anthocyanins $(-0.23$ (95\% confidence interval -0.30 to -0.15$)$ lbs per additional standard deviation/day, 10 $\mathrm{mg})$, flavonoid polymers $(-0.18(-0.28$ to -0.08$) \mathrm{lbs}$ per additional SD/day, $138 \mathrm{mg})$, and flavonols ( -0.16 ( -0.26 to -0.06$) \mathrm{lbs}$ per additional SD/day, $7 \mathrm{mg})$. After additional adjustment for fiber intake, associations remained significant for anthocyanins, proanthocyanidins, and total flavonoid polymers but

\section{WHAT IS ALREADY KNOWN ON THIS TOPIC}

Flavonoids are naturally occurring bioactive compounds that represent a constituent of fruits and vegetables, beyond calorie and macronutrient content, that could potentially influence body weight

Most weight loss studies to date have focused on the flavan-3-ol subclass found in green tea and are limited to small numbers of overweight and obese participants

\section{WHAT THIS STUDY ADDS}

Increased consumption of most flavonoid subclasses was associated with less weight gain

The greatest magnitude of association was observed for anthocyanins, flavonoid polymers, and flavonols

Choosing high flavonoid fruits and vegetables, such as apples, pears, berries, and peppers, may help with weight control.

were attenuated and no longer statistically significant for other subclasses.

\section{CONCLUSIONS}

Higher intake of foods rich in flavonols, flavan-3-ols, anthocyanins, and flavonoid polymers may contribute to weight maintenance in adulthood and may help to refine dietary recommendations for the prevention of obesity and its potential consequences.

\section{Introduction}

Flavonoids are naturally occurring bioactive compounds that represent a constituent of fruits and vegetables, beyond calorie and macronutrient content, that could potentially influence body weight. In a previous food based analysis, we found wide ranging associations between intake of specific fruits and vegetables and weight maintenance. ${ }^{1}$ Among fruits, an increased intake of blueberries, apples, pears, prunes, strawberries, and grapes was inversely associated with weight gain. Increased intake of peppers and celery was also associated with less weight gain. The mechanisms responsible for these benefits and the specific constituents of these fruits and vegetables that may explain these associations are unclear.

The particular fruits and vegetables associated with less weight gain are rich sources of several flavonoid subclasses, particularly flavonols, anthocyanins, and flavones. Animal models and short term human studies provide evidence for underlying mechanisms that relate flavonoids to weight: several flavonoid subclasses have been shown to decrease energy intake, ${ }^{2-5}$ increase glucose uptake in muscle in vivo, ${ }^{6}$ and decrease glucose uptake in adipose tissue in vitro. ${ }^{67}$ Other studies, predominantly focusing on green tea, a rich source of the flavan-3-ol subclass of flavonoids, provide evidence to suggest that flavonoids may decrease fat absorption, ${ }^{89}$ increase energy expenditure, ${ }^{9-12}$ and inhibit adipogenesis. ${ }^{513-15}$

Most weight loss studies to date have focused on the flavan-3-ol subclass found in green tea and are limited to small numbers of overweight and obese participants. Here, we examine, to our knowledge for the first time, the associations between habitual consumption of all flavonoid subclasses and weight gain among 124086 American men and women followed for up to 24 years. The results from this analysis may help to refine previous dietary recommendations and provide people with better guidance on which fruits and vegetables to choose for the prevention of weight gain. Most adults gain weight as they age, and even small increases in weight can have a substantial effect on the risk of 
hypertension, ${ }^{16}$ diabetes, ${ }^{17}$ cardiovascular disease, ${ }^{1819}$ cancer, ${ }^{20}$ and mortality. ${ }^{21}$ Strategies to help people to maintain a healthy weight from childhood onward are therefore critically needed.

\section{Methods}

\section{Study populations}

We used three large prospective cohorts of American men and women from 50 states for this analysis. The Health Professionals Follow-up Study (HPFS) began in 1986 and enrolled 51529 male health professionals aged 40-75 years. ${ }^{22}$ The Nurses' Health Study (NHS) began in 1976 and enrolled 121701 female nurses aged 30-55 years. ${ }^{23}$ The Nurses' Health Study 2 (NHS II) began in 1989 and enrolled 116686 younger female nurses aged $25-42$ years. ${ }^{24}$

We excluded men and women with a history of chronic disease at baseline because of potential disease related weight loss. We considered the following to be chronic diseases: obesity (body mass index $\geq 30$ ), diabetes, cancer, cardiovascular disease, renal disease, pulmonary disease, liver disease, ulcerative colitis, lupus, tuberculosis, multiple sclerosis, amyotrophic lateral sclerosis, and Parkinson's disease. With the exception of obesity and cardiovascular disease, we censored people who developed these conditions during follow-up six years before the date of diagnosis. We censored people who developed cardiovascular disease during follow-up at the date of diagnosis. We did not censor people if they became obese during follow-up.

We temporarily excluded women who were pregnant or lactating for one four year interval and censored people who reported gastric bypass surgery. We excluded people over age 65 at baseline and censored the remaining people when they reached age 65 owing to potential age related sarcopenia. Finally, we excluded men and women with missing baseline lifestyle data or who reported implausible energy intake (men $<800$ or $>4200$ daily calories; women $<600$ or $>3500$ daily calories). Our final analysis included 20525 men from the HPFS, 39423 women from the NHS, and 64138 women from the NHS II (see supplemental table A for specific exclusions and supplemental table B for a comparison of original versus analysis cohorts).

\section{Patient involvement}

No patients were involved in setting the research question or the outcome measures, nor were they involved in the design and implementation of the study. There are no plans to involve patients in the dissemination of the results.

\section{Assessment of weight}

All participants self reported their weight in pounds via a questionnaire every two years. We calculated weight change within each four year period as the difference in weight between the beginning and end of each period, so negative differences indicate weight loss and positive differences indicate weight gain. There were a total of six four year periods in the HPFS and NHS (24 years of follow-up) and five in the NHS II (20 years of follow-up).
Pearson correlation coefficients between self reported weight and technician measured weight were 0.97 among a sample of 140 women in the NHS and 123 men in the HPFS. ${ }^{25}$ We use a conversion factor of 0.454 to convert pounds to $\mathrm{kg}$ in the text.

\section{Assessment of flavonoid intakes}

All participants self reported their diet every four years using a validated, ${ }^{26}$ semiquantitative food frequency questionnaire. We used the US Department of Agriculture (USDA) flavonoid content of foods and proanthocyanidin databases to create a database of the flavonoid content per serving of foods and beverages included on the study food frequency questionnaire. ${ }^{27} 28$ We calculated a person's flavonoid intake as the frequency of consumption of specified portions of flavonoid containing foods multiplied by the flavonoid content (aglycone equivalents) per serving of that food, summed across all foods and beverages, as described previously. ${ }^{29}$

We derived intakes of seven flavonoid subclassesflavanones (eriodictyol, hesperetin, and naringenin), anthocyanins (cyanidin, delphinidin, malvidin, pelargonidin, petunidin, and peonidin), flavan-3-ols (catechin, gallocatechin, epicatechin, epigallocatechin, epicatechin 3-gallate, and epigallocatechin 3-gallate), proanthocyanidins (dimers, trimers, 4-6mers, 7-10mers, and polymers), flavonoid polymers (proanthocyanidins, theaflavins, and thearubigins), flavonols (quercetin, kaempferol, myricetin, and isorhamnetin), and flavones (luteolin and apigenin) - as well as total flavonoids (all subclasses summed). As a sensitivity analysis, we additionally examined flavonoid polymers excluding thearubigins because current quantification methods are somewhat crude. We did not include isoflavones in our analysis because levels are very low $(<3$ $\mathrm{mg} / \mathrm{d}$ ) in the habitual US diet and, from the extensive intervention studies, we know that an isoflavone intake of more than $25 \mathrm{mg} / \mathrm{d}$ is needed for any biological/clinical effect. ${ }^{30} 31$

\section{Assessment of covariates}

Participants reported their lifestyle habits and any recent physician diagnosed diseases via a questionnaire every two years. We included baseline age and body mass index for that particular four year period as covariates in our main models, as well as change in smoking status, physical activity level, ${ }^{32}$ hours of sitting or watching TV, and hours of sleep over the same time period and change in intake of the following foods/nutrients: fried potatoes, juice, whole grains, refined grains, fried foods, nuts, whole fat dairy, low fat dairy, sugar sweetened drinks, diet drinks, sweets, processed meats, non-processed meats, trans fat, alcohol, seafood, and caffeine. Because citrus juices are a main source of both flavone and flavanone intake in this population, we used non-citrus juice rather than all fruit juice as a covariate for analyses of these two flavonoid subclasses. In additional models, we further adjusted for change in total fiber intake (g/day). 


\section{Statistical methods}

We used multivariable generalized linear regression models to examine the association between change in weight (lbs) over four years and change in intake of flavonoid subclasses (standard deviation/day) over the same four year time interval, as described in a previous publication. ${ }^{33}$ We used robust variance to account for within person repeated measures because each person could have contributed up to five time periods, and results for all four year time intervals are averaged. We examined each flavonoid subclass individually and did not mutually adjust for other flavonoid subclasses in our models. We included all other lifestyle factors assessable by questionnaire that we and many others have found to be associated with weight change. We did not include biological factors (such as blood pressure) and drugs because these factors could be mediators (in the causal pathway) or direct correlates of mediators of the effect of diet on weight change.

We truncated change in intake of flavonoids and change in weight at the 0.5 th and 99.5 th centiles to minimize the influence of outliers. The last observation was carried forward for missing values of continuous variables with the exception of diet (main exposure) and weight (main outcome), and indicators were used for missing values of categorical variables. Missing values were carried forward only once for diet and weight, after which the follow-up was censored. We did several sensitivity analyses, including a complete case analysis in which missing values were not carried forward, models that included obese participants, and models additionally adjusting for change in total fiber, change in total calorie intake, and baseline levels of all covariates.

We pooled results from the three cohorts by using the DerSimonian-Laird estimators and the $\mathrm{Q}$ statistic to test for heterogeneity. The three studies are weighted by the inverse of the sum of the study specific variance plus the common between studies variance (random effects pooling). All analyses used SAS version 9.2 and a two tailed $\alpha$ of 0.05 .

\section{Results}

The average age of participants at baseline ranged from 36.3 years in women in the NHS II to 46.9 years in men in the HPFS and 48.5 years in women in the NHS (table 1). Over each four year period, men gained an average of $2.2 \mathrm{lbs}(1 \mathrm{~kg})$, women in the NHS $2.9 \mathrm{lbs}(1.3$ $\mathrm{kg}$ ), and women in the NHS II $4.4 \mathrm{lbs}(2.0 \mathrm{~kg})$. Men had a median intake of $224 \mathrm{mg} / \mathrm{d}$ of total flavonoids, women in the NHS $247 \mathrm{mg} / \mathrm{d}$, and women in the NHS II $236 \mathrm{mg} / \mathrm{d}$. Intake of flavonoid polymers was the highest, ranging from a median of $118 \mathrm{mg} / \mathrm{d}$ to $144 \mathrm{mg} / \mathrm{d}$ across the three cohorts, and intake of flavones was the lowest, with a median of 1.2 to $2.2 \mathrm{mg} / \mathrm{d}$.

\begin{tabular}{|c|c|c|c|c|c|c|}
\hline \multirow[b]{2}{*}{ Characteristics } & \multicolumn{2}{|c|}{$\begin{array}{l}\text { Health Professionals Follow-up Study } \\
(\mathrm{n}=20525)\end{array}$} & \multicolumn{2}{|c|}{ Nurses' Health Study ( $n=39423)$} & \multicolumn{2}{|c|}{ Nurses' Health Study II $(n=64138)$} \\
\hline & Baseline* (1986) & Four year changet & Baseline* (1986) & Four year changet & Baseline* (1991) & Four year changet \\
\hline Age, years & $46.9(2.9)$ & - & $48.5(2.4)$ & - & $36.3(3.4)$ & - \\
\hline Body mass index, $\mathrm{kg} / \mathrm{m}^{2}$ & $24.6(1.4)$ & - & $23.6(1.4)$ & - & $22.8(2.2)$ & - \\
\hline Weight, lbs & $174(13)$ & $2.2(-14.0-20.0)$ & $140(9)$ & $2.9(-14.0-25.0)$ & $137(16)$ & $4.4(-10.0-32.3)$ \\
\hline Physical activity, MET-hr/wk & $23.5(19.5)$ & $5.1(-46.0-100.0)$ & $15.0(9.9)$ & $1.6(-34.7-42.6)$ & $21.6(22.1)$ & $0.4(-26.1-22.6)$ \\
\hline Alcohol, servings/d & $0.9(0.7)$ & $0.0(-2.1-1.6)$ & $0.5(0.4)$ & $0.0(-1.3-0.9)$ & $0.3(0.4)$ & $0.0(-0.5-0.8)$ \\
\hline Caffeine, mg/d & $236(141)$ & $-11(-372-306)$ & $305(112)$ & $-29(-354-270)$ & $241(167)$ & $-12(-280-224)$ \\
\hline Flavonols, $\mathrm{mg} / \mathrm{d}$ & $11.7(7.9-17.0)$ & $2.1(-14.3-26.9)$ & $12.1(8.1-18.1)$ & $1.6(-14.0-27.0)$ & $14.2(9.3-23.3)$ & $1.3(-19.5-18.0)$ \\
\hline Flavones, mg/d & $2.2(1.2-3.1)$ & $0.1(-3.4-2.6)$ & $2.1(1.2-3.1)$ & $0.0(-2.8-2.2)$ & $1.2(0.7-2.1)$ & $0.1(-1.4-2.2)$ \\
\hline Flavanones, mg/d & $41.7(16.1-64.9)$ & $-0.1(-79.3-78.9)$ & $37.6(14.9-63.7)$ & $-0.7(-66.1-62.0)$ & $21.7(9.3-48.6)$ & $-1.3(-42.5-47.8)$ \\
\hline Flavan-3-ols, mg/d & $23.9(13.5-51.0)$ & $0.5(116.3-115.7)$ & $24.2(13.2-71.6)$ & $-0.9(-113.6-133.2)$ & $26.1(13.0-73.6)$ & $-0.8(-119.4-79.4)$ \\
\hline Anthocyanins, mg/d & $7.7(3.9-16.2)$ & $2.4(-24.6-28.7)$ & $11.5(5.2-19.6)$ & $1.8(-28.4-28.3)$ & $5.7(3.1-14.6)$ & $4.5(-17.5-34.6)$ \\
\hline Polymers, mg/d & $117.6(63.4-214.4)$ & $7.1(-344.7-370.8)$ & $134.9(72.6-254.4)$ & $1.3(-342.6-396.5)$ & $143.5(76.5-267.6)$ & $3.9(-363.6-252.3)$ \\
\hline Total flavonoids, mg/d & $223.6(138.1-362.2)$ & $11.9(-472.6-531.4)$ & $247.1(149.8-416.0)$ & $2.5(-480.3-547.0)$ & $235.9(136.9-410.6)$ & $8.2(-506.2-360.3)$ \\
\hline Total fruit without juice, servings/d & $1.5(0.7)$ & $0.1(-1.9-2.1)$ & $1.5(0.5)$ & $0.0(-1.9-1.9)$ & $1.2(0.7)$ & $0.0(-1.3-1.5)$ \\
\hline Total vegetables, servings/d & $2.9(1.0)$ & $0.2(-2.6-3.7)$ & $3.2(0.8)$ & $0.1(-2.6-3.4)$ & $3.1(1.6)$ & $0.0(-2.7-3.0)$ \\
\hline Whole fat dairy, servings/d & $1.0(0.6)$ & $-0.1(-2.3-1.4)$ & $1.2(0.5)$ & $-0.1(-2.3-1.2)$ & $0.8(0.6)$ & $0.0(-1.4-1.1)$ \\
\hline Low fat dairy, servings/d & $0.8(0.6)$ & $-0.1(-2.0-1.7)$ & $0.8(0.4)$ & $0.1(-1.5-2.0)$ & $1.1(0.8)$ & $0.0(-1.4-1.7)$ \\
\hline Seafood, servings/d & $0.4(0.2)$ & $0.0(-0.5-0.6)$ & $0.3(0.1)$ & $0.0(-0.5-0.4)$ & $0.3(0.2)$ & $0.0(-0.4-0.3)$ \\
\hline Whole grains, servings/d & $1.5(0.8)$ & $0.0(-2.3-2.9)$ & $0.8(0.4)$ & $0.1(-1.6-2.2)$ & $1.3(0.9)$ & $0.0(-1.5-1.3)$ \\
\hline Refined grains, servings/d & $1.2(0.6)$ & $0.0(-2.1-2.1)$ & $1.2(0.4)$ & $0.0(-1.7-1.7)$ & $1.3(0.7)$ & $-0.1(-1.3-1.7)$ \\
\hline Nuts, servings/d & $0.3(0.3)$ & $0.0(-0.9-0.8)$ & $0.1(0.1)$ & $0.0(-0.6-0.5)$ & $0.1(0.1)$ & $0.1(-0.2-0.7)$ \\
\hline Sugar sweetened drinks, servings/d & $0.3(0.4)$ & $0.0(-0.9-0.9)$ & $0.2(0.2)$ & $0.0(-0.6-0.7)$ & $0.3(0.5)$ & $0.0(-0.9-0.8)$ \\
\hline Zero calorie soda, servings/d & $0.5(0.6)$ & $0.0(-1.5-1.6)$ & $0.5(0.4)$ & $0.0(-1.2-1.5)$ & $0.9(1.1)$ & $-0.1(-1.8-1.5)$ \\
\hline Juice, servings/d & $0.8(0.5)$ & $0.0(-1.6-1.5)$ & $0.7(0.4)$ & $0.0(-1.3-1.3)$ & $0.7(0.6)$ & $-0.1(-1.2-1.0)$ \\
\hline Sweets, servings/d & $1.3(0.8)$ & $0.0(-2.4-2.3)$ & $1.1(0.5)$ & $0.0(-1.8-2.2)$ & $1.1(0.8)$ & $-0.1(-1.5-1.4)$ \\
\hline Processed meats, servings/d & $0.4(0.2)$ & $0.0(-0.8-0.6)$ & $0.3(0.1)$ & $0.0(-0.6-0.4)$ & $0.2(0.2)$ & $0.0(-0.4-0.4)$ \\
\hline Non-processed meats, servings/d & $0.6(0.3)$ & $0.0(-0.9-0.7)$ & $0.6(0.2)$ & $0.0(-0.7-0.6)$ & $0.5(0.3)$ & $0.0(-0.5-0.5)$ \\
\hline Trans fat, \% & $1.3(0.3)$ & $0.0(-0.7-1.3)$ & $1.7(0.3)$ & $-0.2(-1.1-0.9)$ & $1.6(0.5)$ & $-0.2(-1.0-0.5)$ \\
\hline
\end{tabular}

*Mean (SD) or median (interquartile range).

tMean (1st- 99 th centile range). 


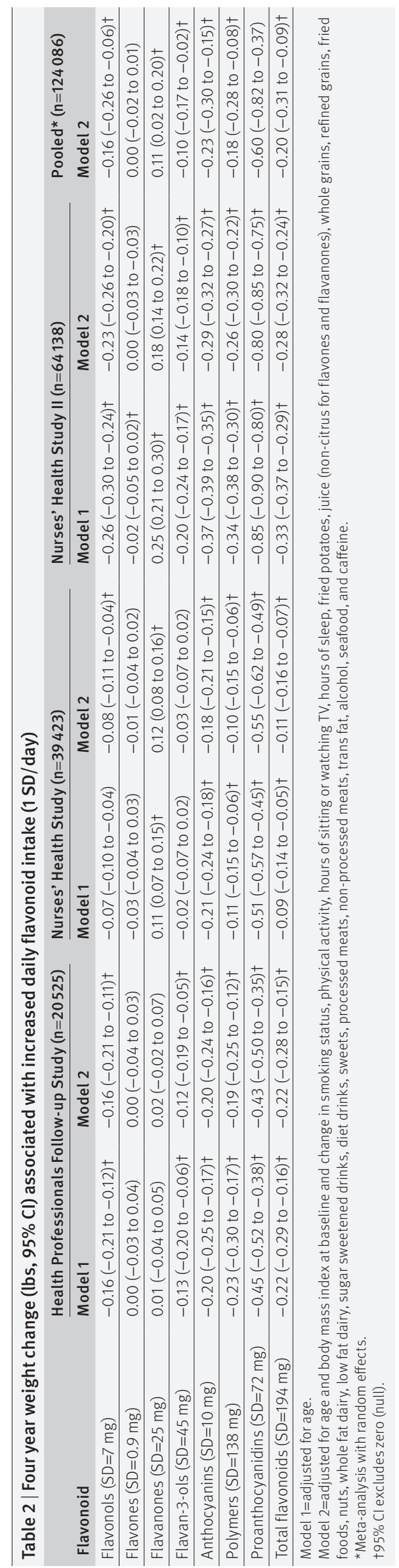

Increased intake of most flavonoid subclasses, with the exception of flavones and flavanones, was inversely associated with weight gain (table 2). The strongest magnitude of association was seen for anthocyanins, flavonoid polymers (including proanthocyanidins alone), and flavonols; each greater standard deviation of daily intake was associated with 0.16 to $0.23 \mathrm{lbs}$ (0.07$0.10 \mathrm{~kg}$ ) less weight gained over four year intervals. Eighty three per cent of flavanone and $44 \%$ of flavone intake was derived from citrus fruits and juices. When we adjusted intakes of flavones and flavanones for total juice intake rather than non-citrus juice, an important contributor to weight gain in these cohorts, ${ }^{33}$ the observed associations between intake of these two subclasses and weight gain were stronger, inverse, and statistically significant (table 3, model $4 v$ model 5).

These associations remained significant for anthocyanins and flavonoid polymers (including proanthocyanidins alone) when we further adjusted for change in total fiber intake but not for flavonols, flavanones, and flavan-3-ols. In these models, increased fiber intake was inversely associated with weight change in all three cohorts. When we excluded thearubigins from total flavonoid polymers, the association with weight change was stronger in fully adjusted models: -0.61 (95\% confidence interval -0.83 to -0.38 ) lbs per increased SD $(76 \mathrm{mg})$.

Models with and without adjustment for change in other aspects of diet were very similar (table 3, model 2 $v$ model 3). All associations were virtually identical when we additionally included change in total energy intake as a covariate in our models. In addition, models that included obese participants (supplemental table C) and models that used a complete case analysis in which missing values were not carried forward (supplemental table D) showed very similar results.

In these cohorts, the main food sources of anthocyanins were blueberries and strawberries, while flavan-3ols and their oligomers (polymers) were mainly derived from tea and apples. As noted above, orange juice and oranges were the main sources of flavanone and flavone intakes, and tea and onions were the main sources of flavonols in the habitual diet (figure 1). Dietary sources of the different flavonoid subclasses were similar across cohorts, with the exception of beer providing flavan-3ols in the HPFS, peppers providing flavones in the NHS, and red wine providing flavones in the NHS II and HPFS. The food frequency questionnaire did not include all fruits and vegetables, and some known rich sources of flavonoids, such as blackberries and raspberries, were not specifically included.

\section{Discussion}

We found that increased consumption of most flavonoid subclasses was associated with less weight gain among men and women aged 27-65 followed for up to 24 years. The greatest magnitude of association was observed for anthocyanins, flavonoid polymers, and flavonols. These associations remained statistically significant for anthocyanins and flavonoid polymers (including proanthocyanidins alone) even after further adjustment for fiber intake, which was inversely 


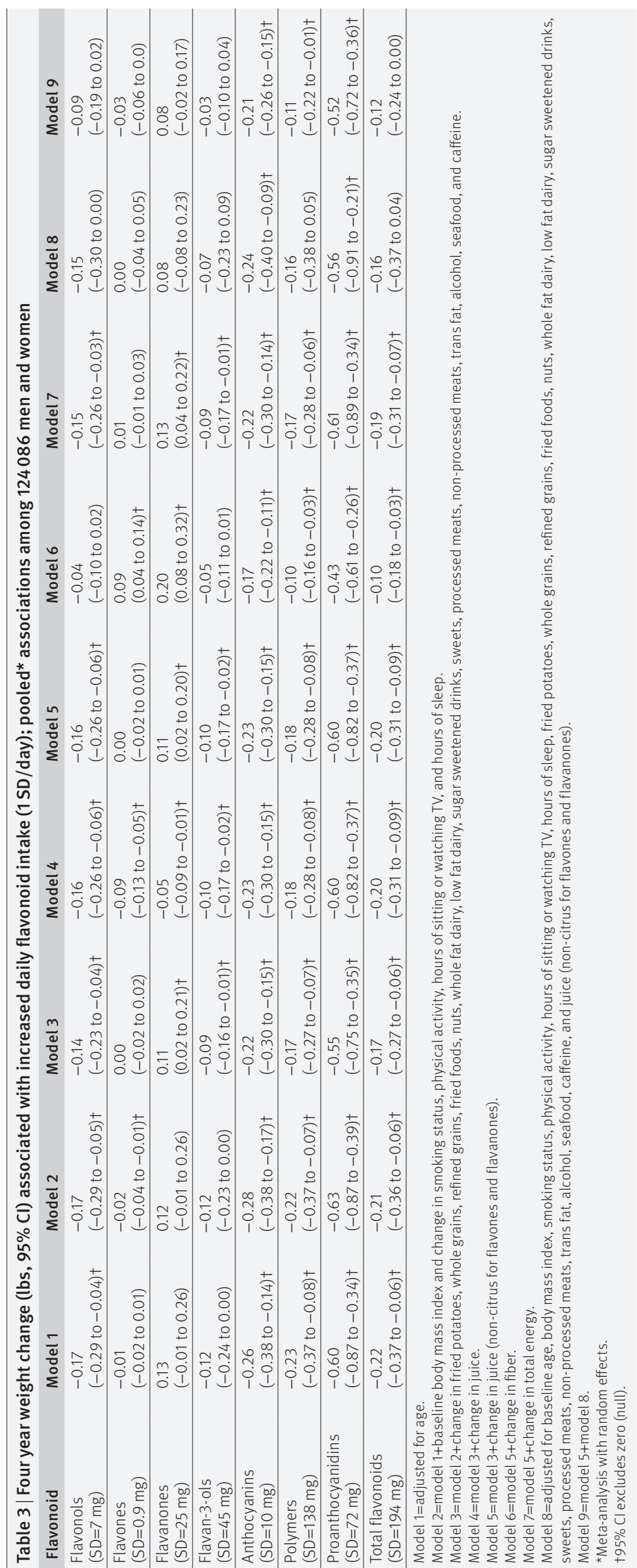

associated with weight change in all three cohorts, indicating that high anthocyanin and flavonoid polymer food sources may be associated with less weight gain through mechanisms other than fiber content.

The magnitudes of these associations were small, less than a pound $(<0.5 \mathrm{~kg})$ per increased daily standard deviation, but a single serving per day of many fruits can often provide more than one standard deviation (supplemental table E). For example, one half cup of blueberries provides about $121 \mathrm{mg}$ or about 12 standard deviations of anthocyanins. Furthermore, losing even small amounts of weight can improve health: losing just 11-22 lbs (5.0-10 kg) is associated with a decrease in blood pressure, ${ }^{1618}$ and reducing body mass index by 1-3 $\mathrm{kg} / \mathrm{m}^{2}$ is associated with a $2-13 \%$ lower risk of cardiovascular disease events. ${ }^{19}$ Similarly, preventing even small amounts of weight gain could have an important public health impact: gaining $10 \mathrm{lbs}(4.5 \mathrm{~kg})$ or more between the ages of 40 and 60 increased the risk of developing diabetes by $40-70 \%,{ }^{17}$ and a meta-analysis of 221 studies found a 24-59\% increased risk of several cancers. ${ }^{20}$

\section{Comparison with other studies}

In a cohort setting, Hughes et al found that women with the highest intake of three flavonoid subclasses, flavones, flavonols, and catechins (a flavan-3-ol), had a smaller increase in body mass index over 14 years than those with lower intakes. ${ }^{34}$ These associations were not present in men, possibly owing to lower flavonoid intake and smaller increases in body mass index over time compared with women. In our study population, intake of flavonoids was only slightly lower among men than in women, and body mass index also increased more slowly over time among men; however, we detected inverse associations among both men and women. Similar to Hughes et al, however, we saw the strongest inverse associations among younger women (NHS II).

To date, human weight loss trials have examined only supplements containing flavan-3-ols and many have been too short to test meaningful differences in weight loss. ${ }^{3536}$ Among 80 overweight people with diabetes, no difference was found in weight between the groups randomized to decaffeinated green tea $(856 \mathrm{mg} / \mathrm{d}$ epigallocatechin gallate) versus placebo for one year. ${ }^{37}$ On the other hand, weight and subcutaneous fat decreased among 102 overweight/obese people taking $8 \mathrm{~g} / \mathrm{d}$ oolong tea for six weeks, but there was no placebo comparison group in this study. ${ }^{36}$ Often, flavan-3-ol interventions are combined with other interventions such as physical activity, caffeine, or insulin, and their effects are hard to tease apart. Comparing results from trials that run for much shorter time periods or use supplements instead of whole foods is also difficult because long term higher intake of specific fruits and vegetables is generally most relevant to public health interventions.

\section{Strengths and limitations of study}

Our study has some limitations. Although our validated food frequency questionnaire specifies portion size, measurement error will be present with any assessment 


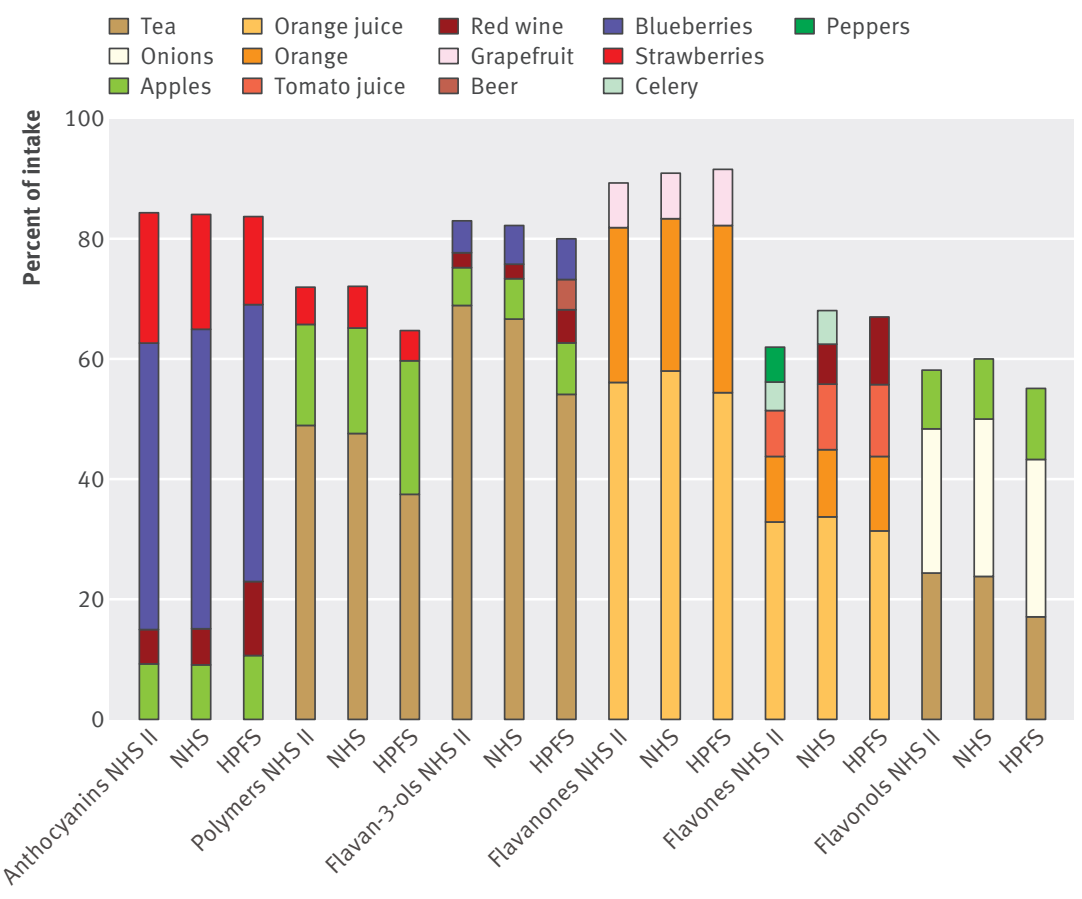

Fig 1 | Major dietary sources of flavonoids by subclass, averaged for 1986-2010 in Health Professionals Follow-up Study (HPFS) and Nurses' Health Study (NHS) and 1991-2007 in NHS II.

of diet and the flavonoid content of foods varies depending on ripeness, storage conditions, food processing, and season, which may introduce additional measurement error. As dietary thearubigin intakes are crudely measured, we did further analysis excluding thearubigins from the flavonoid polymer subclass and found a stronger inverse association with weight change ( $-0.61 \mathrm{lbs}$ per increased daily SD over four years versus $-0.18 \mathrm{lbs})$.

Furthermore, our food frequency questionnaire did not capture all food sources of flavonoids, but it did capture the main sources present in the habitual diet. Our results could underestimate true associations if people who gained weight in the beginning of a four year period modified their diet in response and began to eat more fruits and vegetables, and hence more flavonoids, in order to lose weight (reverse causality). On the other hand, our results could overestimate true associations if people who gained weight stopped eating fruits and vegetables. In addition, although we incorporated a comprehensive list of confounders, residual confounding is possible owing to imperfect measurement of confounders and potential unmeasured/ unknown confounders. The source of confounding most difficult to control is other constituents of the foods that are high in flavonoids; in our analysis, control for fiber intake substantially attenuated the observed associations, except for associations with anthocyanins and flavonoid polymers. Finally, our results may be generalizable only to people of similar age, race, and socioeconomic status.

Strengths of our study include the measurement of all major flavonoid subclasses, the inclusions of more than 100000 men and women, a wide age range, and up to 24 years of follow-up. Furthermore, each participant completed a validated, semiquantitative food frequency questionnaire up to seven times during follow-up. We additionally had data on a comprehensive set of potential dietary and lifestyle confounders; this and the restriction of this population to participants with higher education and income reduced residual confounding due to socioeconomic status. Finally, our results were consistent across both sexes and different ages.

\section{Conclusions and policy implications}

These data may help to refine previous dietary recommendations for the prevention of obesity and its potential consequences. Our results suggest that choosing high flavonoid fruits and vegetables, such as apples, pears, berries, and peppers, may help with weight control. Most Americans consume less than one cup (less than two servings) of fruits and less than two cups of vegetables daily, ${ }^{38}$ and juice and potatoes are major contributors to intake. ${ }^{38}$ Beyond increasing intake to current recommendations of two cups of fruit and 2.5 cups of vegetables per day, ${ }^{39}$ people may be able to maximize their health benefit by including optimal fruits and vegetables in their daily diets.

We acknowledge the Channing Division of Network Medicine, Department of Medicine, Brigham and Women's Hospital and Harvard Medical School. We thank the participants of the Nurses' Health and Health Professionals Follow-up Studies for their ongoing dedication.

Contributors: MLB, EBR, and AC conceived and designed the experiments. MLB, WCW, FBH, EBR, and AC conducted the experiments. MLB analyzed the data and wrote the first draft of the manuscript. KJM, WCW, FBH, EBR, and AC contributed to the writing of the manuscript. All authors agree with the manuscript's results and conclusions. MLB is the guarantor.

Funding: This study was supported by grants P01 CA87969, R01 CA49449, R01 HL034594, R01 HL088521, UM1 CA176726, R01 CA67262, UM1 CA167552, R01 HL35464, and UM1 CA186107 from the National Institutes of Health; the Biotechnology, Biological Sciences Research Council (BBSRC), UK (reference BB/J004545/1); and the project "Diet and prevention of ischemic heart disease: a translational approach" (DIPI, www.dipi.dk), which is supported by the Danish Council for Strategic Research (today, Innovation Fund Denmark) (contract 0603-00488B). AC is a Royal Society Wolfson Research Merit Award holder. The funders played no role in the study design, data collection, analysis and interpretation of data, writing of the manuscript, or the decision to submit the article for publication.

Competing interests: All authors have completed the ICMJE uniform disclosure form at www.icmje.org/coi_disclosure.pdf (available on request from the corresponding author) and declare: support for the study as described above; ERB and AC have a collaborative grant, unrelated to this project, to conduct observational and experimental studies of blueberries and cardiovascular disease health outcomes from the US Highbush Blueberry Council; no other relationships or activities that could appear to have influenced the submitted work. Ethical approval: The study protocol was approved by the Institutional Review Board of the Brigham and Women's Hospital and by the Harvard T.H. Chan School of Public Health Human Subjects Committee Review Board (ID 2008P000327). All participants provided voluntary responses to mailed questionnaires that served as informed consent.

Transparency declaration: The lead author (the manuscript's guarantor) affirms that the manuscript is an honest, accurate, and transparent account of the study being reported; that no important aspects of the study have been omitted; and that any discrepancies from the study as planned (and, if relevant, registered) have been explained.

Data sharing: Health Professionals Follow-up Study, Nurses' Health Study, and Nurses' Health Study II data may be used in collaboration with a principal investigator. Please see the study websites for more information: www.hsph.harvard.edu/hpfs/hpfs_collaborators.htm and www.channing.harvard.edu/nhs/?page_id=52. 
This is an Open Access article distributed in accordance with the Creative Commons Attribution Non Commercial (CC BY-NC 3.0) license, which permits others to distribute, remix, adapt, build upon this work non-commercially, and license their derivative works on different terms, provided the original work is properly cited and the use is noncommercial. See: http://creativecommons.org/licenses/by-nc/3.0/.

1 Bertoia ML, Mukamal KJ, Cahill LE et al. Changes in intake of fruits and vegetables and weight change in United States men and women followed for up to 24 years: analysis from three prospective cohort studies. PLoS Med 2015;12: e1001878. doi:10.1371/journal.pmed.1001878

2 Stendell-Hollis NR, Thomson CA, Thompson PA, Bea JW, Cussler EC, Hakim IA. Green tea improves metabolic biomarkers, not weight or body composition: a pilot study in overweight breast cancer survivors. J Hum Nutr Diet 2010;23: 590-600. doi:10.1111/j.1365-277X.2010.01078.X

3 Josic J, Olsson AT, Wickeberg J, Lindstedt S, Hlebowicz J. Does green tea affect postprandial glucose, insulin and satiety in healthy subjects: a randomized controlled trial. Nutr / 2010;9: 63. doi:10.1186/1475-2891-9-63

4 Carter BE, Drewnowski A. Beverages containing soluble fiber, caffeine, and green tea catechins suppress hunger and lead to less energy consumption at the next meal. Appetite 2012;59: 755-61. doi:10.1016/j.appet.2012.08.015

5 Badshah H, Ullah I, Kim SE, Kim TH, Lee HY, Kim MO. Anthocyanins attenuate body weight gain via modulating neuropeptide $Y$ and GABAB1 receptor in rats hypothalamus. Neuropeptides 2013;47: 347-53. doi:10.1016/j.npep.2013.06.001

6 Ashida H, Furuyashiki T, Nagayasu $\mathrm{H}$ et al. Anti-obesity actions of green tea: possible involvements in modulation of the glucose uptake system and suppression of the adipogenesis-related transcription factors. Biofactors 2004:22: 135-40. doi:10.1002/biof.5520220126

7 Strobel P, Allard C, Perez-Acle T, Calderon R, Aldunate R, Leighton F. Myricetin, quercetin and catechin-gallate inhibit glucose uptake in isolated rat adipocytes. Biochem / 2005;386: 471-8. doi:10.1042/ BJ20040703

8 Dulloo AG, Duret C, Rohrer D et al. Efficacy of a green tea extract rich in catechin polyphenols and caffeine in increasing 24-h energy expenditure and fat oxidation in humans. Am / Clin Nutr 1999;70: 1040-5.

9 Westerterp-Plantenga MS, Lejeune MP, Kovacs EM. Body weight loss and weight maintenance in relation to habitual caffeine intake and green tea supplementation. Obes Res 2005;13: 1195-204. doi:10.1038/oby.2005.142

10 Komatsu T, Nakamori M, Komatsu K et al. Oolong tea increases energy metabolism in Japanese females. I Med Invest 2003;50: 170-5.

11 Choo JJ. Green tea reduces body fat accretion caused by high-fat diet in rats through beta-adrenoceptor activation of thermogenesis in brown adipose tissue. J Nutr Biochem 2003;14: 671-6. doi:10.1016/j. jnutbio.2003.08.005

12 Auvichayapat P, Prapochanung M, Tunkamnerdthai $O$ et al. Effectiveness of green tea on weight reduction in obese Thais: A randomized, controlled trial. Physiol Behav 2008;93: 486-91. doi:10.1016/j.physbeh.2007.10.009

13 Wolfram S, Raederstorff D, Wang Y, Teixeira SR, Elste V, Weber P. TEAVIGO (epigallocatechin gallate) supplementation prevents obesity in rodents by reducing adipose tissue mass. Ann Nutr Metab 2005;49: 54-63. doi:10.1159/000084178

14 Wu T, Qi X, Liu Y et al. Dietary supplementation with purified mulberry (Morus australis Poir) anthocyanins suppresses body weight gain in high-fat diet fed C57BL/6 mice. Food Chem 2013;141: 482-7. doi:10.1016/j.foodchem.2013.03.046

15 Moon J, Do HJ, Kim OY, Shin MJ. Antiobesity effects of quercetin-rich onion peel extract on the differentiation of 3T3-L1 preadipocytes and the adipogenesis in high fat-fed rats. Food Chem Toxicol 2013;58: 347-54. doi:10.1016/j.fct.2013.05.006

16 Huang Z, Willett WC, Manson JE et al. Body weight, weight change, and risk for hypertension in women. Ann Intern Med 1998;128: 81-8. doi:10.7326/0003-4819-128-2-199801150-00001

17 Holbrook TL, Barrett-Connor E, Wingard DL. The association of lifetime weight and weight control patterns with diabetes among men and women in an adult community. Int J Obes 1989;13: 723-9.

18 Czernichow S, Mennen L, Bertrais S, Preziosi P, Hercberg S, Oppert JM. Relationships between changes in weight and changes in cardiovascular risk factors in middle-aged French subjects: effect of dieting. Int J Obes Relat Metab Disord 2002;26: 1138-43. doi:10.1038/sj.ijo.0802059
19 Panico S, Palmieri L, Donfrancesco C et al. Preventive potential of body mass reduction to lower cardiovascular risk: the Italian Progetto CUORE study. Prev Med 2008;47: 53-60. doi:10.1016/j.ypmed.2008.01.023

20 Renehan AG, Tyson M, Egger M, Heller RF, Zwahlen M. Body-mass index and incidence of cancer: a systematic review and meta-analysis of prospective observational studies. Lancet 2008;371: 569-78. doi:10.1016/S0140-6736(08)60269-X

21 Adams KF, Schatzkin A, Harris TB et al. Overweight, obesity, and mortality in a large prospective cohort of persons 50 to 71 years old. $N$ Engl / Med 2006:355: 763-78. doi:10.1056/NEIMoa055643

22 Rimm EB, Giovannucci EL, Willett WC et al. Prospective study of alcohol consumption and risk of coronary disease in men. Lancet 1991;338: 464-8. doi:10.1016/0140-6736(91)90542-W

23 Willett WC, Stampfer MJ, Colditz GA, Rosner BA, Hennekens CH, Speizer FE. Dietary fat and the risk of breast cancer. N Engl J Med 1987;316: 22-8. doi:10.1056/NEJM198701013160105

24 Solomon CG, Willett WC, Carey VJ et al. A prospective study of pregravid determinants of gestational diabetes mellitus. JAMA 1997;278: 1078-83. doi:10.1001/jama.1997.03550130052036

25 Rimm EB, Stampfer MJ, Colditz GA, Chute CG, Litin LB, Willett WC. Validity of self-reported waist and hip circumferences in men and women. Epidemiology 1990;1: 466-73. doi:10.1097/00001648-199011000-00009

26 Rimm EB, Giovannucci EL, Stampfer MJ, Colditz GA, Litin LB, Willett WC. Reproducibility and validity of an expanded self-administered semiquantitative food frequency questionnaire among male health professionals. Am J Epidemiol 1992:135: 1114-26, discussion 1127-36.

27 US Department of Agriculture. USDA database for the flavonoid content of selected foods: release 2.1. 2007. www.ars.usda.gov/ SP2UserFiles/Place/80400525/Data/Flav/Flav02-1.pdf.

28 US Department of Agriculture. USDA database for the proanthocyanidin content of selected foods. 2004. http://www.ars. usda.gov/SP2UserFiles/Place/80400525/Data/PA/PA.pdf.

29 Cassidy A, O'Reilly EJ, Kay C et al. Habitual intake of flavonoid subclasses and incident hypertension in adults. Am J Clin Nutr 2011;93: 338-47. doi:10.3945/ajcn.110.006783

30 de Kleijn MJ, van der Schouw YT, Wilson PW et al. Intake of dietary phytoestrogens is low in postmenopausal women in the United States: the Framingham study(1-4). J Nutr 2001;131: 1826-32.

31 Setchell KD, Cassidy A. Dietary isoflavones: biological effects and relevance to human health. I Nutr 1999:129: 758S-67S.

32 Wolf AM, Hunter DJ, Colditz GA et al. Reproducibility and validity of a self-administered physical activity questionnaire. Int J Epidemiol 1994:23: 991-9. doi:10.1093/ije/23.5.991

33 Mozaffarian D, Hao T, Rimm EB, Willett WC, Hu FB. Changes in diet and lifestyle and long-term weight gain in women and men. N Engl J Med 2011;364: 2392-404. doi:10.1056/NEJMoa1014296

34 Hughes LA, Arts IC, Ambergen T et al. Netherlands Cohort Study. Higher dietary flavone, flavonol, and catechin intakes are associated with less of an increase in BMl over time in women: a longitudinal analysis from the Netherlands Cohort Study. Am J Clin Nutr 2008;88: 1341-52.

35 Mielgo-Ayuso J, Barrenechea L, Alcorta P, Larrarte E, Margareto J, Labayen I. Effects of dietary supplementation with epigallocatechin-3gallate on weight loss, energy homeostasis, cardiometabolic risk factors and liver function in obese women: randomised, double-blind, placebo-controlled clinical trial. Br J Nutr 2014;111: 1263-71. doi:10.1017/S0007114513003784

36 He RR, Chen L, Lin BH, Matsui Y, Yao XS, Kurihara H. Beneficial effects of oolong tea consumption on diet-induced overweight and obese subjects. Chin J Integr Med 2009;15: 34-41. doi:10.1007/ s11655-009-0034-8

37 Hsu CH, Liao YL, Lin SC, Tsai TH, Huang Cl, Chou P. Does supplementation with green tea extract improve insulin resistance in obese type 2 diabetics? A randomized, double-blind, and placebo-controlled clinical trial. Altern Med Rev 2011;16:157-63.

38 Kimmons J, Gillespie C, Seymour J, Serdula M, Blanck HM. Fruit and vegetable intake among adolescents and adults in the United States: percentage meeting individualized recommendations. Medscape J Med 2009;11: 26.

39 U.S. Department of Agriculture and U.S. Department of Health and Human Services. Dietary guidelines for Americans, 2010.7th ed. Government Printing Office, 2010.

\section{Supplementary tables}

